\title{
Breathing pattern and carbon dioxide retention in severe chronic obstructive pulmonary disease
}

Massimo Gorini, Gianni Misuri, Antonio Corrado, Roberto Duranti, Iacopo Iandelli, Eduardo De Paola, Giorgio Scano

\begin{abstract}
Background - The factors leading to chronic hypercapnia and rapid shallow breathing in patients with severe chronic obstructive pulmonary disease (COPD) are not completely understood. In this study the interrelations between chronic carbon dioxide retention, breathing pattern, dyspnoea, and the pressure required for breathing relative to inspiratory muscle strength in stable COPD patients with severe airflow obstruction were studied.
\end{abstract}

Methods - Thirty patients with COPD in a clinically stable condition with forced expiratory volume in one second $\left(F_{E V}\right)$ of $<1$ litre were studied. In each patient the following parameters were assessed: (1) dyspnoea scale rating, (2) inspiratory muscle strength by measuring minimal pleural pressure (PPLmin), and (3) tidal volume (VT), flow, pleural pressure swing (PPLsw), total lung resistance (RI), dynamic lung elastance (ELdyn), and positive end expiratory alveolar pressure (PEEPi) during resting breathing.

Results - Arterial carbon dioxide tension $\left(\mathrm{PaCO}_{2}\right)$ related directly to RI/PPLmin, and ELdyn/PPLmin, and inversely to VT and PPLmin. There was no relationship between $\mathrm{PaCO}_{2}$ and functional residual capacity (FRC), total lung capacity (TLC), or minute ventilation. PEEPi was similar in eucapnic and hypercapnic patients. Expressing $\mathrm{PaCO}_{2}$ as a combined function of VT and PPLmin (stepwise multiple regression analysis) explained $71 \%$ of the variance in $\mathbf{P a C O}_{2}$. Tidal volume was directly related to inspiratory time (TI), and $T_{I}$ was inversely related to the pressure required for breathing relative to inspiratory muscle strength (PPLsw, \%Pplmin). There was an association between the severity of dyspnoea and both the increase in PPLsw (\%PPLmin) and the shortening in $\mathbf{T r}$.

Conclusions - The results indicate that, in stable patients with COPD with severe airflow obstruction, hypercapnia is associated with shallow breathing and inspiratory muscle weakness, and rapid and shallow breathing appears to be linked to both a marked increase in the pressure required for breathing relative to inspiratory muscle strength and to the severity of the breathlessness.

(Thorax 1996;51:677-683)
Keywords: chronic obstructive pulmonary disease, hypercapnia, breathing pattern, respiratory muscle weakness, breathlessness.

The mechanisms which lead to chronic hypercapnia in patients with chronic obstructive pulmonary disease (COPD) are not completely understood. Although carbon dioxide retention is dependent on the severity of airways obstruction, there is considerable variability in the relationship between arterial carbon dioxide tension $\left(\mathrm{PaCO}_{2}\right)$ and forced expiratory volume in one second $\left(\mathrm{FEV}_{1}\right) .{ }^{1}$ Other factors such as ventilation-perfusion mismatch, ${ }^{2}$ abnormalities in ventilatory control, ${ }^{34}$ respiratory muscle weakness, ${ }^{56}$ the pattern of breathing, ${ }^{6-10}$ and dynamic pulmonary hyperinflation ${ }^{11}$ have been reported to contribute to chronic carbon dioxide retention in patients with COPD. In this connection Bégin and Grassino have recently shown that, in a large group of patients with COPD with a variable degree of airflow obstruction, the probability of developing hypercapnia increases with the severity of the obstruction, obesity, and inspiratory muscle weakness. ${ }^{12}$ In that study, however, only half of the variation in $\mathrm{PaCO}_{2}$ could be explained, even when $\mathrm{PaCO}_{2}$ was expressed as a function of as many as five variables including total lung resistance, dead space, body weight, dynamic lung elastance, and maximal inspiratory mouth pressure. Thus, in the accompanying editorial Rochester hypothesised that other factors must be involved in carbon dioxide retention in patients with COPD and that rapid shallow breathing is likely to be one of these. ${ }^{13}$

Although a more rapid and shallower pattern of breathing has frequently been observed in hypercapnic than in eucapnic patients with COPD, ${ }^{6-10}$ the mechanisms responsible for this breathing strategy have not been clearly defined. Increased activation of vagal afferent nerves consequent to chronic bronchitis ${ }^{7-9}$ and chronic hypoxaemia ${ }^{14}$ may contribute to rapid shallow breathing. More recently it has been hypothesised that rapid and shallow breathing in patients with COPD is the consequence of an excessive load imposed on the inspiratory muscles. ${ }^{1315}$ In these patients a reduction in tidal volume could allow them to reduce the pressure required for breathing relative to inspiratory muscle strength, thus minimising respiratory effort and dyspnoea, and avoiding fatigue. ${ }^{13}$ The shallow breathing reduces alveolar ventilation and predisposes to hypercapnia. $^{713}$ To our knowledge, however, no previous studies have specifically examined the interrelations between breathing pattern, breathlessness, and relative pressure required 
A<smiles>[AlH2]CCCC[AlH2]</smiles>
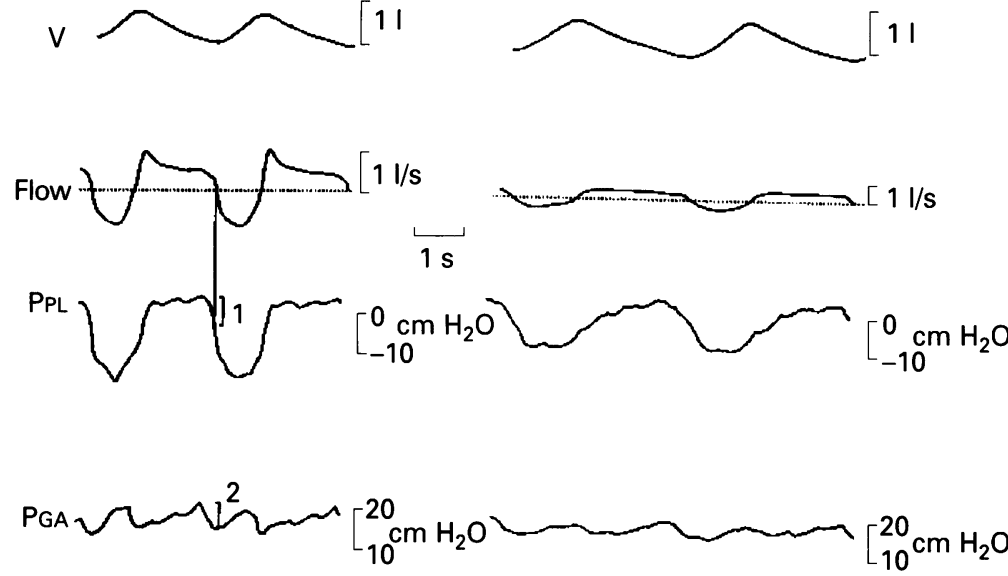

Figure 1 Record of volume (V) (increased upward), flow, pleural pressure (PPL) and gastric pressure (PGA) during quiet breathing in two representative patients with severe COPD with (A) hypercapnia (patient no. 22 in table 1 ) and (B) eucapnia (patient no. 1 in table 1). Dynamic positive end expiratory alveolar pressure (1) and the rise in PGA during expiration (2) are illustrated in $(A)$.

for breathing in patients with COPD when breathing at rest.

In this study we have analysed the relationship between chronic carbon dioxide retention and the breathing pattern, respiratory muscle load, and the pressure required for breathing relative to inspiratory muscle strength, together with the factors associated with rapid and shallow breathing, in 30 stable COPD patients with severe airflow obstruction.

\begin{abstract}
Methods
SUBJECTS

The study was performed in 30 male outpatients with COPD. ${ }^{16}$ Inclusion criteria were severe airflow obstruction $\left(\mathrm{FEV}_{1}<1\right.$ litre) and age $<80$ years. Exclusion criteria were: (1) left ventricular dysfunction; (2) neuromuscular disorders; (3) neoplasia; (4) thoracic surgery; (5) moderate to severe obesity (body weight $>130 \%$ of ideal weight $\left.{ }^{17}\right) ;(6)$ clinical symptoms suggestive of sleep apnoea syndrome; and (7) functional evidence of restrictive lung disease (total lung capacity $<80 \%$ of predicted value). All patients gave informed consent to the protocol as approved by the institution's ethics committee. Each patient had been in a clinically stable condition for at least four weeks before the study.

Respiratory symptoms were assessed in each patient by using the standardised questionnaire of the European Community for Coal and Steel. ${ }^{18}$ In particular, dyspnoea was graded according to a modified Medical Research Council (MRC) scale ranging from 1 (breathlessness going up one flight of stairs at normal pace) to 4 (breathlessness when dressing or undressing). ${ }^{18}$
\end{abstract}

\section{MEASUREMENTS}

All measurements were made while the patients were seated in a comfortable high-backed armchair. Spirometric values were measured by the standard technique using a water-sealed spirometer (Godart); functional residual capacity (FRC) was measured by the helium dilution technique. Predicted values for lung function variables are those proposed by the European Community for Coal and Steel. ${ }^{19}$ Arterial blood gas tensions were measured with an ABL-3 analyser (Radiometer, Copenhagen, Denmark).

Airflow was measured with a no. 3 Fleisch pneumotachograph and a Validyne pressure transducer (Validyne Corp, Northridge, California, USA) and the flow signal was integrated into the volume. The dead space of the mouthpiece and flow meter was $70 \mathrm{ml}$ and the equipment resistance was $0.92 \mathrm{~cm} \mathrm{H}_{2} \mathrm{O} / 1 / \mathrm{s}$. From the spirometric results we derived breath-by-breath time and volume components of the respiratory cycle: inspiratory time (TI), expiratory time (TE), total time of the respiratory cycle (TTOT), and tidal volume (VT). The mean inspiratory flow $(\mathrm{Vt} / \mathrm{Tr})$, duty cycle (TI/Tтот), and respiratory frequency $(f)$ were also calculated.

Mouth pressure ( $\left.\mathrm{P}_{M}\right)$ was measured through a side port at the mouthpiece using a differential pressure transducer (Validyne, Northridge, California, USA). Oesophageal pressure (POES) was measured with a conventional balloon catheter system ${ }^{20}$ connected to a Validyne differential pressure transducer as previously described. ${ }^{21}$ The balloon was positioned in the mid oesophagus and contained $0.4 \mathrm{ml}$ of air. Oesophageal pressure was used as an index of pleural pressure (PPL). In 15 patients gastric pressure (PGA) was simultaneously measured with a similar balloon catheter system connected to a second differential pressure transducer. This balloon was positioned in the stomach $65-70 \mathrm{~cm}$ from balloon tip to nares and contained $2 \mathrm{ml}$ of air. Transpulmonary pressure $(\mathrm{PL})$ was obtained as the difference between PM and PPL. All signals were recorded on a multichannel chart recorder.

Total lung resistance $(\mathrm{RL})$ and dynamic lung elastance (ELdyn) were measured during resting breathing. Total lung resistance was obtained using the isovolume method. ${ }^{22}$ Dynamic lung elastance was determined by dividing the difference in PL between points of zero flow by VT. To evaluate end expiratory alveolar pressure we used the indirect method recently described by Haluszka and coworkers ${ }^{11}$ and Dal Vecchio and colleagues ${ }^{23}$ rather than the direct method of airways occlusion. In fact, awake subjects react to airways occlusion in an unpredictable fashion so that no reliable measurement of alveolar pressure can be obtained. We thus looked for the presence of a time lag between the fall in PPL at the onset of the inspiratory effort and the onset of inspiratory airflow and measured the negative deflection in PPL that preceded the start of inspiratory flow (fig 1). This negative deflection in PPL will be referred to here as PEEPi for consistency with previous investigations. ${ }^{112324}$ We also assessed the change in PGA resulting from the contraction of the abdominal muscles during expiration in 15 patients. In agreement with Ninane and colleagues ${ }^{24}$ the increase in PGA which occurred during the expiratory phase of the breathing cycle (PGAexp) was taken 
Table 1 Anthropometric characteristics, clinical symptoms, pulmonary function data, and inspiratory muscle strength in 30 patients with COPD and severe airflow obstruction

\begin{tabular}{|c|c|c|c|c|c|c|c|c|c|c|}
\hline \multirow{2}{*}{$\begin{array}{l}\text { Patient } \\
\text { no. }\end{array}$} & \multirow{2}{*}{$\begin{array}{l}\text { Age } \\
\text { (years) }\end{array}$} & \multirow{2}{*}{$\begin{array}{l}\text { Weight } \\
(\% I W)\end{array}$} & \multirow{2}{*}{$\begin{array}{l}\text { Dyspnoea } \\
\text { (grade) }\end{array}$} & \multicolumn{2}{|l|}{$F E V_{1}$} & \multirow{2}{*}{$\begin{array}{l}V C \\
\text { (\%pred) }\end{array}$} & \multirow{2}{*}{$\begin{array}{l}F R C \\
\text { (\%pred) }\end{array}$} & \multirow{2}{*}{$\begin{array}{l}\text { PPLmin } \\
\left(\mathrm{cmH}_{2} \mathrm{O}\right)\end{array}$} & \multirow{2}{*}{$\begin{array}{l}\mathrm{PaO}_{2} \\
(\mathrm{kPa})\end{array}$} & \multirow{2}{*}{$\begin{array}{l}\mathrm{PaCO}_{2} \\
(\mathrm{kPa})\end{array}$} \\
\hline & & & & (l) & (\%pred) & & & & & \\
\hline 1 & 69 & $111 \cdot 5$ & 3 & 0.53 & $20 \cdot 4$ & $72 \cdot 0$ & $141 \cdot 2$ & 77 & $11 \cdot 1$ & $5 \cdot 7$ \\
\hline 2 & 69 & 125.0 & 3 & 0.83 & 29.9 & 87.0 & 150.6 & 58 & 10.0 & 5.8 \\
\hline 3 & 58 & 121.0 & 2 & 0.80 & $29 \cdot 5$ & $81 \cdot 0$ & $141 \cdot 2$ & 78 & $10 \cdot 0$ & $5 \cdot 0$ \\
\hline 4 & 61 & 110.7 & 4 & 0.73 & $23 \cdot 6$ & $90 \cdot 0$ & $179 \cdot 4$ & 83 & $9 \cdot 2$ & 5.9 \\
\hline 5 & 80 & $100 \cdot 8$ & 2 & 0.70 & $27 \cdot 1$ & 98.0 & 156.5 & 56 & $11 \cdot 3$ & 5.6 \\
\hline 6 & 71 & $117 \cdot 3$ & 3 & 0.80 & $33 \cdot 0$ & $124 \cdot 0$ & $160 \cdot 0$ & 56 & $10 \cdot 1$ & $5 \cdot 8$ \\
\hline 7 & 70 & $94 \cdot 4$ & 2 & 0.73 & $26 \cdot 2$ & 68.0 & 145.8 & 43 & $9 \cdot 6$ & 6.0 \\
\hline 8 & 67 & $84 \cdot 1$ & 2 & $0 \cdot 70$ & $25 \cdot 1$ & $94 \cdot 1$ & $155 \cdot 3$ & 80 & $10 \cdot 6$ & $6 \cdot 0$ \\
\hline 9 & 56 & $66 \cdot 8$ & 4 & 0.53 & $16 \cdot 0$ & $43 \cdot 0$ & $161 \cdot 0$ & 53 & $7 \cdot 5$ & 5.9 \\
\hline 10 & 53 & $115 \cdot 0$ & 3 & 0.80 & $23 \cdot 8$ & $62 \cdot 0$ & 140.9 & 84 & $11 \cdot 4$ & $5 \cdot 7$ \\
\hline 11 & 63 & $101 \cdot 4$ & 3 & 0.85 & $28 \cdot 3$ & $53 \cdot 0$ & $175 \cdot 0$ & 50 & $8 \cdot 7$ & $5 \cdot 5$ \\
\hline 12 & 63 & 85.0 & 3 & 0.98 & $37 \cdot 0$ & 110.0 & $206 \cdot 6$ & 74 & $11 \cdot 0$ & $5 \cdot 0$ \\
\hline 13 & 64 & $125 \cdot 0$ & 2 & 0.90 & $31 \cdot 3$ & 56.0 & $157 \cdot 4$ & 68 & $12 \cdot 4$ & $6 \cdot 0$ \\
\hline 14 & 63 & 101.0 & 3 & 0.52 & $17 \cdot 3$ & 53.0 & 150.0 & 75 & $9 \cdot 6$ & 5.6 \\
\hline 15 & 74 & $78 \cdot 0$ & 3 & 0.48 & $19 \cdot 0$ & $44 \cdot 0$ & 163.0 & 20 & $7 \cdot 7$ & $7 \cdot 7$ \\
\hline 16 & 68 & $100 \cdot 0$ & 3 & 0.84 & $30 \cdot 0$ & $80 \cdot 2$ & 183.0 & 69 & $6 \cdot 8$ & $6 \cdot 5$ \\
\hline 17 & 75 & 99.0 & 4 & 0.67 & $26 \cdot 0$ & 58.0 & $187 \cdot 0$ & 50 & $7 \cdot 7$ & $6 \cdot 5$ \\
\hline 18 & 65 & $79 \cdot 0$ & 3 & 0.82 & $37 \cdot 0$ & $58 \cdot 1$ & 140.0 & 38 & $8 \cdot 0$ & $7 \cdot 7$ \\
\hline 19 & 70 & $80 \cdot 0$ & 3 & 0.60 & $24 \cdot 0$ & $54 \cdot 2$ & 161.0 & 49 & $8 \cdot 8$ & $7 \cdot 2$ \\
\hline 20 & 71 & $80 \cdot 8$ & 2 & 0.51 & $17 \cdot 0$ & $27 \cdot 0$ & 159.0 & 42 & 6.9 & $7 \cdot 5$ \\
\hline 21 & 72 & $90 \cdot 2$ & 4 & 0.76 & $24 \cdot 0$ & $59 \cdot 1$ & $152 \cdot 0$ & 40 & $5 \cdot 7$ & $8 \cdot 0$ \\
\hline 22 & 63 & 114.0 & 4 & 0.64 & $19 \cdot 4$ & $50 \cdot 0$ & $168 \cdot 3$ & 51 & $8 \cdot 2$ & $7 \cdot 7$ \\
\hline 23 & 53 & $80 \cdot 0$ & 4 & 0.59 & $19 \cdot 0$ & $68 \cdot 0$ & 196.0 & 50 & $6 \cdot 5$ & 6.9 \\
\hline 24 & 80 & $101 \cdot 0$ & 3 & 0.60 & $26 \cdot 8$ & $99 \cdot 1$ & 178.0 & 50 & $8 \cdot 0$ & $7 \cdot 1$ \\
\hline 25 & 63 & $81 \cdot 7$ & 4 & 0.43 & $16 \cdot 0$ & 63.0 & $148 \cdot 0$ & 42 & $8 \cdot 2$ & $7 \cdot 1$ \\
\hline 26 & 58 & $93 \cdot 8$ & 4 & 0.32 & 11.5 & $66 \cdot 0$ & $207 \cdot 5$ & 40 & $9 \cdot 6$ & $6 \cdot 7$ \\
\hline 27 & 60 & $85 \cdot 0$ & 3 & 0.50 & $19 \cdot 0$ & $57 \cdot 0$ & $194 \cdot 4$ & 44 & $7 \cdot 2$ & 8.0 \\
\hline 28 & 62 & $102 \cdot 0$ & 2 & 0.75 & $24 \cdot 0$ & $63 \cdot 0$ & $150 \cdot 0$ & 61 & $10 \cdot 7$ & $6 \cdot 1$ \\
\hline 29 & 73 & $90 \cdot 0$ & 3 & 0.95 & $39 \cdot 6$ & $83 \cdot 0$ & $144 \cdot 0$ & 62 & 10.5 & $6 \cdot 7$ \\
\hline 30 & 64 & $88 \cdot 0$ & 4 & 0.71 & $24 \cdot 7$ & 73.9 & $205 \cdot 3$ & 37 & $8 \cdot 0$ & $7 \cdot 7$ \\
\hline
\end{tabular}

$\% \mathrm{IW}=\%$ of ideal weight; PPLmin $=$ minimal pleural pressure.

as a reflection of the mechanical effect of abdominal muscle contraction (fig 1).

Inspiratory muscle strength was assessed by measuring minimal (that is, greatest negative) inspiratory pleural pressure (PPLmin) at FRC during both maximal inspiratory efforts against an obstructed mouthpiece ${ }^{25}$ and during sniff manoeuvres. $^{26}$ The patients were repeatedly encouraged to try as hard as possible and they had a visual feedback of generated pressure. ${ }^{27}$ Both PrLmin manoeuvres were repeated until three measurements with less than $5 \%$ variability were recorded. The highest Pplmin value obtained was used for analysis.

PROTOCOL

Treatment was withheld for 12 hours before the study and all subjects were tested in the afternoon. Before the experiments each subject was well acquainted with the laboratory and equipment. Lung function tests were performed first and then, after a 40 minute rest period, an arterial blood sample was obtained and changes in volume, flow, PM, PPL, and PGA were recorded during three periods of quiet breathing over 30 minutes. Finally, tests of respiratory muscle strength were performed in each patient. It is important to emphasise that patients had not previously been involved in respiratory experiments; furthermore, during the periods of resting breathing each subject was distracted with non-rhythmic music to avoid any acoustic feedback.

DATA ANALYSIS

Volume and time components of the respiratory cycle, inspiratory PrL swings (PPLsw), $R_{L}, E_{L}-$ dyn, PEEPi and PGAexp were averaged in each patient over 30 consecutive breaths from each run. Unless otherwise specified, data are presented as means (SE). Single and stepwise multiple regression analyses were performed to assess relationships between variables. The proportion of total variance in the dependent variable accounted for by the predictor variable(s) is reported as the square of correlation coefficient $\left(r^{2}\right)$, expressed as a percentage. Data comparisons were performed using the Student's unpaired $t$ test and one-way analysis of variance (ANOVA) when appropriate. A p value of $<0.05$ was considered statistically significant.

\section{Results}

Anthropometric, clinical, pulmonary function data, and PPLmin of patients are shown in table 1. Fourteen patients (nos 1-14) were eucapnic $\left(\mathrm{PaCO}_{2} \leq 6 \mathrm{kPa}\right)$ and 16 (nos 15-30) were hypercapnic $\left(\mathrm{PaCO}_{2}>6 \mathrm{kPa}\right)$. The highest PrLmin was obtained by the sniff manoeuvre in 18 patients (nos 2-4, 6-8, 10-14, 16, 18-22, and 28 ) and by inspiratory effort against an obstructed mouthpiece in 12 . Body weight was significantly lower in hypercapnic than in eucapnic patients $(90 \cdot 1(2 \cdot 7)$ and $104 \cdot 2(4 \cdot 6) \%$ of ideal weight, respectively, $p=0.01$ ), and six hypercapnic patients and one eucapnic patient had a body weight below $85 \%$ of ideal weight. The tracings of volume, flow, PPL, and PGA obtained during quiet, resting breathing in two representative subjects with hypercapnia and eucapnia are shown in fig 1 . The breathing was more rapid and shallower, and PpLsw was greater in the hypercapnic patient than in the eucapnic patient. In both patients PEEPi was associated with an increase in gastric pressure during expiration indicating abdominal muscle contraction. 
Table 2 Correlation coefficients of $\mathrm{PaCO}_{2}$ to respiratory function parameters in 30 patients with severe COPD

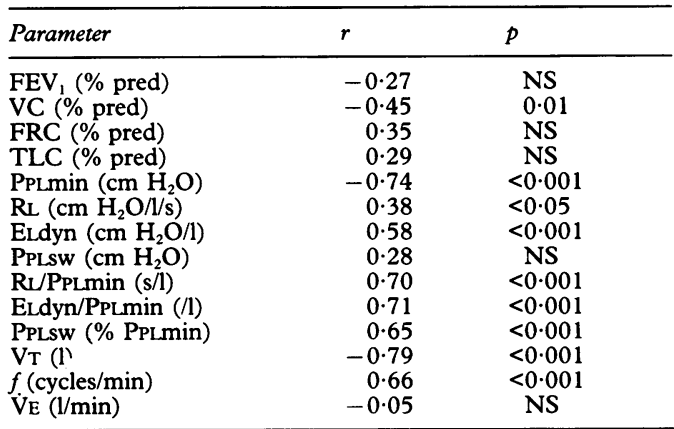

$\mathrm{FEV}_{1}=$ forced expiratory volume in one second; $\mathrm{VC}=$ vital capacity; FRC = functional residual capacity; TLC = total lung capacity; PPLmin =minimal pleural pressure; $R_{L}=$ total lung resistance; ELdyn=dynamic lung elastance; PPLSw = pleura pressure swing; VT =tidal volume; $f=$ respiratory frequency; $\dot{\mathrm{V}}_{\mathrm{E}}=$ minute ventilation.

\section{FACTORS INFLUENCING CARBON DIOXIDE}

\section{RETENTION}

The correlation coefficients of $\mathrm{PaCO}_{2}$ with different mechanical, inspiratory muscle, and ventilatory parameters are shown in table 2 . $\mathrm{PaCO}_{2}$ did not relate to $\mathrm{FEV}_{1}$, TLC, or FRC, whereas a weak but significant inverse relationship was found between $\mathrm{PaCO}_{2}$ and VC. As shown in fig 2, there was a significant inverse relationship between $\mathrm{PaCO}_{2}$ and PPLmin. Inspiratory PPLsw was greater in hypercapnic than in eucapnic patients $(14.8(1 \cdot 0)$ and 11.3 $(1 \cdot 2) \mathrm{cm} \mathrm{H}_{2} \mathrm{O}$, respectively, $\left.\mathrm{p}<0 \cdot 05\right)$. $\mathrm{PaCO}_{2}$ related well to $\mathrm{RL} /$ Pplmin and Eldyn/PrLmin, the higher the $\mathrm{PaCO}_{2}$ the greater both the resistive and elastic loads relative to inspiratory muscle strength. Positive end expiratory alveolar pressure was present in all patients but one and was similar in eucapnic and hypercapnic patients $\left(2 \cdot 8(0.6)\right.$ and $3.4(0.4) \mathrm{cm} \mathrm{H}_{2} \mathrm{O}$, respectively). In the 15 patients in whom PGA was measured there was a significant relationship between PEEPi and expiratory rise in gastric pressure $\left(r^{2}=66.7 \%, \mathrm{p}<0.001\right.$, fig 3$)$.

There was a significant inverse relationship between $\mathrm{PaCO}_{2}$ and VT such that $\mathrm{PaCO}_{2}$ was highest in patients with the smallest VT (fig 4).

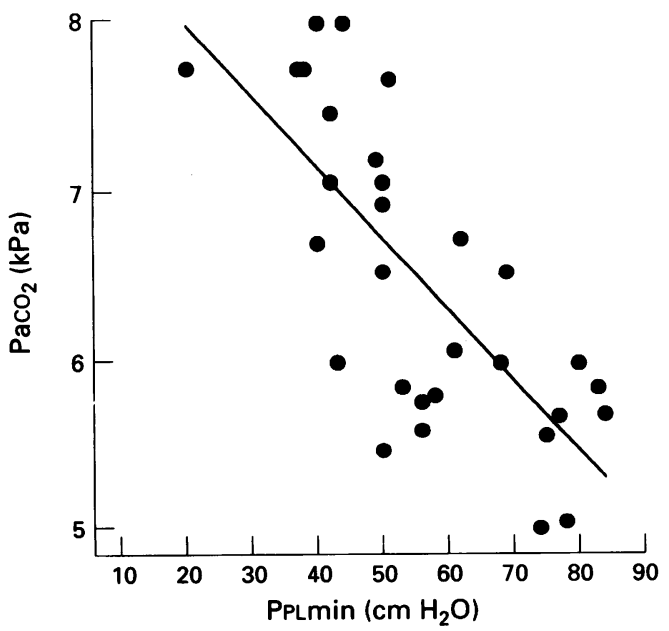

Figure 2 Relationship between $\mathrm{PaCO}_{2}$ and minimal pleural pressure (PPLmin) in 30 patients with severe COPD. The solid line is the regression line and the closed circles are individual data points.

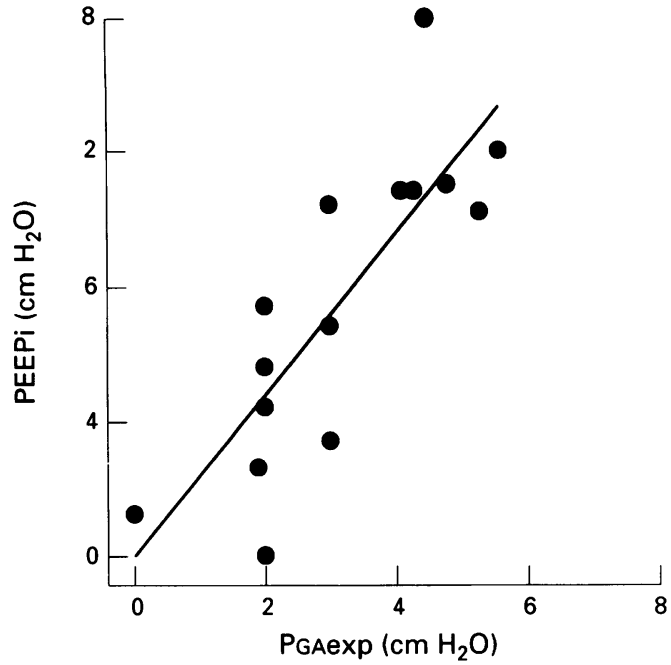

Figure 3 Relationship between dynamic positive end expiratory alveolar pressure (PEEPi) and expiratory rise in gastric pressure (PGAexp) in 15 patients with severe $C O P D$. The solid line is the regression line and the closed circles are individual data points.

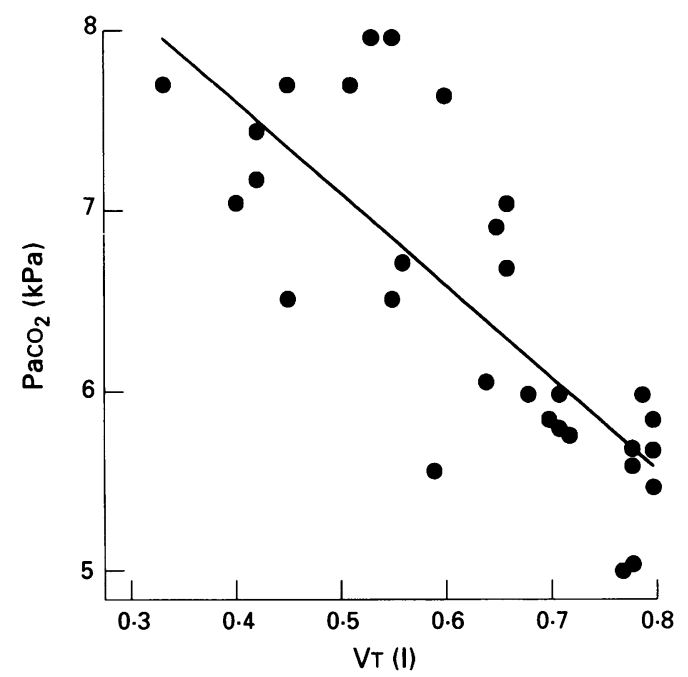

Figure 4 Relationship between $\mathrm{PaCO}_{2}$ and tidal volume (VT) in 30 patients with severe COPD. The solid line is the regression line and the closed circles are individual data points.

On the contrary, no significant relationship was found between $\mathrm{PaCO}_{2}$ and minute ventilation.

The variables that related significantly to $\mathrm{PaCO}_{2}$ were entered into a multiple regression analysis. The regression equation generated by stepwise multiple regression analysis for $\mathrm{PaCO}_{2}$ included VT and PrLmin. These variables accounted for $70.9 \%$ of the total variance in $\mathrm{PaCO}_{2}$. The coefficient and $\mathrm{F}$ value of both variables in the final equation, and the model $r^{2}$ as each variable is added, are shown in table 3.

Table 3 Stepwise multiple regression analysis for $\mathrm{PaCO}_{2}$

\begin{tabular}{lllll}
\hline Variable & Coefficient & Model $r^{2}(\%)$ & $F$ & $p$ value \\
\hline VT & -3.45 & 60.5 & 61.6 & $<0.001$ \\
PPLmin & -0.02 & 70.9 & 11.1 & $<0.005$ \\
Constant & 9.93 & & & \\
\hline
\end{tabular}

$\mathrm{VT}=$ tidal volume PPLmin $=$ minimal pleural pressure 


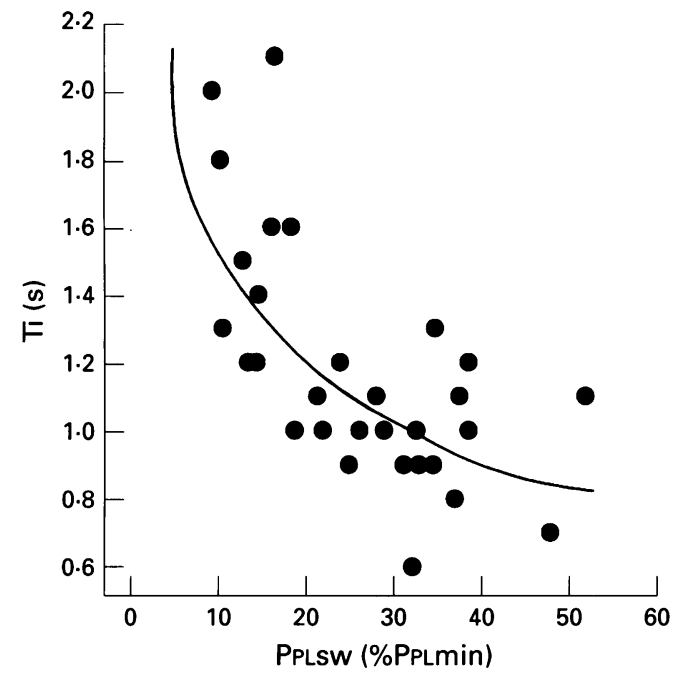

Figure 5 Relationship between inspiratory time (TI) and inspiratory pleural pressure swing expressed as a percentage of minimal pleural pressure (PPLSw (\% PPLmin)) in 30 patients with severe COPD. The solid line is the regression line and the closed circles are individual data points.

FACTORS INFLUENCING BREATHING PATTERN Compared with eucapnic patients, hypercapnic patients exhibited a significantly smaller VT $(0.74(0.02)$ and $0.52(0.03) \mathrm{l}$, respectively, $\mathrm{p}<0.001)$, a significantly greater $f(15 \cdot 1(0.7)$ and $22.7(0.9)$ cycles $/ \mathrm{min}$, respectively, $\mathrm{p}<0.001$ ), and a similar minute ventilation.

Both resistive $\left(\mathrm{RL}_{\mathrm{L}}\right)$ and dynamic elastic (ELdyn) loads for the respiratory muscles were significantly greater in hypercapnic than in eucapnic patients $(11.9(0.7)$ versus $9 \cdot 1(0.8) \mathrm{cm}$ $\mathrm{H}_{2} \mathrm{O} / \mathrm{l} / \mathrm{min}, \mathrm{p}=0.01$; and $11.7(1 \cdot 0)$ versus $6 \cdot 7$ $\left.(0.5) \mathrm{cm} \mathrm{H}_{2} \mathrm{O} / \mathrm{l}, \mathrm{p}<0.001\right), \mathrm{VT} / \mathrm{TI}$ being similar in the two groups $(0.57(0.03)$ and $0.53(0.02)$ $1 / \mathrm{s}$, respectively).

Tidal volume was directly related to $\mathrm{TI}$ $\left(r^{2}=55.3 \%, p<0.001\right)$, indicating that shallow breathing in severe COPD patients was mainly accounted for by changes in respiratory timing. As shown in fig 5, there was a significant curvilinear (multiplicative) relationship between $\mathrm{TI}$ and PPLSW (\%Pplmin) $\left(r^{2}=49.6 \%\right.$, $\mathrm{p}<0.001)$, such that the shortening in TI was associated with the increase in the pressure required for breathing relative to inspiratory muscle strength. A weak, direct relationship $\left(r^{2}=25 \cdot 3 \%, \mathrm{p}=0.005\right)$ was observed between $\mathrm{TI}$ and $\mathrm{PaO}_{2}$. However, stepwise multiple regression analysis showed that expressing $\mathrm{TI}$ as a combined function of PPLsw (\%PPLmin) and $\mathrm{PaO}_{2}$ did not significantly increase the explained variance in TI beyond the contribution of Pplsw (\%Pplmin).

Inspiratory time and PPLsw (\%PPLmin) in patients grouped according to dyspnoea scale rating are shown in fig 6 . There was a significant association between dyspnoea rating and both PPLSW (\%PPLmin) ( $<<0.001$, ANOVA) and $T I$ $(\mathrm{p}<0.005$, ANOVA), the patients with severe dyspnoea exhibiting the greatest Pplsw (\%PPLmin) and the shortest TI.

\section{Discussion}

The main findings of this study can be summarised as follows: (1) in patients with stable COPD with severe airflow obstruction there is a significant association between hypercapnia and both shallow breathing and inspiratory muscle weakness, and these variables explain more than $70 \%$ of the variance in $\mathrm{PaCO}_{2}$; (2) VT relates well to $\mathrm{TI}$, and the latter is significantly related to PPLsw (\%PPLmin), the shorter the TI the greater the pressure required for breathing relative to inspiratory muscle strength; (3) there is a significant association between the severity of dyspnoea and both the increase in PPLsw (\%PpLmin) and the shortening in $\mathrm{TI}$.

\section{CRITIQUE OF METHODS}

Before discussing these results it is pertinent to consider the limitations of the procedure used in this study. Inspiratory muscle strength was evaluated by measuring PPLmin during voluntary manoeuvres. In this condition the development of PrLmin depends not only on the strength and coordination of inspiratory muscles, but also on the motivation and cooperation of subjects. To minimise this prob-
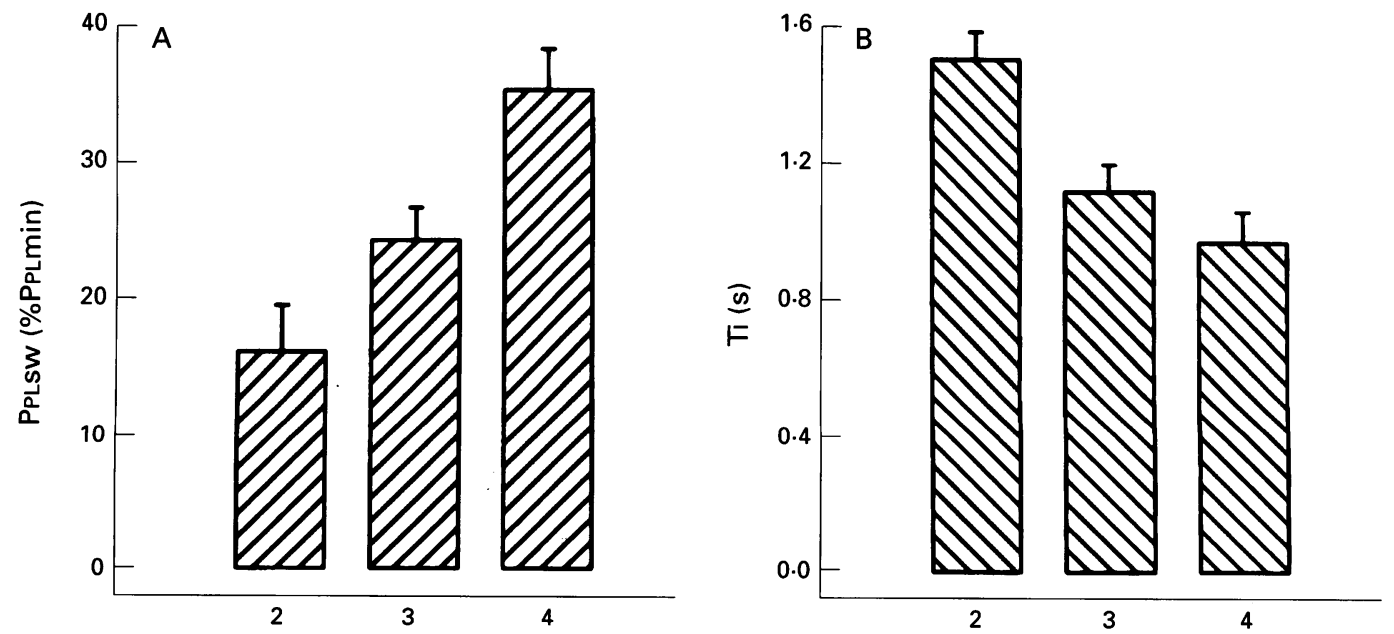

Dyspnoea scale rating

Figure 6 (A) Mean (SE) inspiratory pleural pressure swing expressed as a percentage of minimal pleural pressure (PPLsw (\%PPLmin)) and (B) inspiratory time (TI) in 30 patients with severe COPD grouped by dyspnoea scale rating. 
lem, PpLmin was obtained from different manoeuvres (see Methods) and all patients had a visual feedback of generated pressure as suggested by Laporta and Grassino. ${ }^{27}$

The breathing pattern was assessed with a noseclip and mouthpiece that may increase VT and decrease respiratory frequency compared with natural breathing. ${ }^{28}$ In particular, when the breathing pattern in patients with COPD was evaluated from body surface movements using the technique of inductive plethysmography, ${ }^{1029} \mathrm{VT}$ was found to be somewhat lower than that observed in studies in which only a mouthpiece was used..$^{6-9}$ In our study the simultaneous measurement of volume, flow and PPL was necessary to assess the relationships between $\mathrm{PaCO}_{2}$, breathing pattern, and mechanical factors such as RI, ELdyn, and PEEPi during quiet breathing. To minimise the effects of the mouthpiece, however, we used a mouthpiece and flowmeter system with a small dead space; in addition, subjects were well acquainted with the laboratory and equipment before the experiments and each patient was distracted with non-rhythmic music to avoid any acoustic feedback during periods of quiet breathing. Furthermore, our data showing a significant inverse relationship between $\mathrm{PaCO}_{2}$ and VT in patients with severe COPD are in agreement with those obtained by Loveridge and coworkers using inductive plethysmography. ${ }^{10}$

\section{CARBON DIOXIDE RETENTION IN SEVERE COPD} The present data showing that $\mathrm{PaCO}_{2}$ did not relate significantly to $\mathrm{FEV}_{1}$ and related only weakly to VC are in line with previous studies ${ }^{112}$ indicating that many patients with COPD with severe airflow obstruction do not develop chronic hypercapnia.

Our results showed that, in stable patients with severe COPD, $\mathrm{PaCO}_{2}$ related directly to both RL/PPLmin and Eldyn/PpLmin, and inversely to both VT and PPLmin. Furthermore, multiple regression analysis showed that expressing $\mathrm{PaCO}_{2}$ as a combined function of VT and PPLmin explained more than $70 \%$ of the total variance in $\mathrm{PaCO}_{2}$. These results confirm and extend previous reports ${ }^{5-1012}$ in that chronic carbon dioxide retention is primarily associated with shallow breathing and inspiratory muscle weakness in patients with stable COPD with severe airflow obstruction. It is important to stress however that, although correlation is an essential prerequisite to establish a cause and effect relationship, correlation alone does not imply causation. In particular, whether chronic hypercapnia itself may affect inspiratory muscle contractility in patients with severe COPD, as shown for acute respiratory acidosis in normal subjects, ${ }^{30}$ remains to be established.

Bégin and Grassino ${ }^{12}$ have recently reported that obesity enhanced the probability of hypercapnia at any level of airflow obstruction and inspiratory muscle weakness in more than 300 patients with COPD with a variable degree of airflow obstruction. In the present study, however, hypercapnic patients had a significantly lower body weight than eucapnic patients; furthermore, in agreement with a previous report, ${ }^{5}$ we found that body weight had a direct relationship with PPLmin $\left(r^{2}=28.8 \%, \mathrm{p}<0.005\right)$ such that underweight was associated with inspiratory muscle weakness. Differences in the selection of patients may partly explain these discrepancies. In fact, in the present study only patients with severe airflow obstruction were included, and obesity - that may be associated with carbon dioxide retention even in the absence of lung disease $\mathrm{e}^{31}$ - was an exclusion criterion.

It has recently been shown ${ }^{1123}$ that, in most patients with stable COPD breathing at rest, alveolar pressure at end expiration is positive. Assuming that expiration is a passive process and, as a consequence, that alveolar pressure at end expiration is the elastic recoil pressure of the respiratory system, these studies concluded that dynamic pulmonary hyperinflation is frequent in patients with stable COPD. ${ }^{1123}$ Furthermore, Haluszka and colleagues have shown that, in patients with stable COPD, $\mathrm{PaCO}_{2}$ was significantly related to PEEPi which suggests that dynamic pulmonary hyperinflation could play a part in chronic carbon dioxide retention. ${ }^{11}$ In the present study a positive alveolar pressure at end expiration was present in all but one patient and was similar in eucapnic and hypercapnic patients. In agreement with Ninane and coworkers ${ }^{24}$ we observed that expiration was an active process in many patients, and there was a close relationship between the expiratory rise in gastric pressure and PEEPi, such that alveolar pressure at end expiration was greater as the expiratory rise in gastric pressure was larger. These data indicate that, in patients with severe COPD, positive alveolar pressure at end expiration is, to a large extent, the consequence of the transmission through the relaxed diaphragm of the rise in abdominal pressure due to abdominal muscle contraction. The present findings therefore confirm that dynamic PEEPi cannot be used to quantify the degree of dynamic pulmonary hyperinflation in many patients with severe COPD. ${ }^{24}$

\section{BREATHING PATTERN IN SEVERE COPD}

Compared with eucapnic COPD patients, those with hypercapnia exhibited more rapid and shallower breathing. Inspiratory PPLsw was greater in hypercapnic than eucapnic patients and, although the elastic and resistive loads were higher in the former than in the latter, VT/TI was similar in the two groups. These data are in agreement with previous reports $^{6-81229}$ and clearly suggest that shallow breathing in patients with severe COPD is not associated with a reduction in inspiratory neural drive. Furthermore, in our patients VT was related directly to $T_{I}$, indicating that a small tidal volume was primarily the consequence of alteration in respiratory timing.

The mechanisms leading to alteration in respiratory timing in patients with COPD have not yet been clearly defined. It has been shown that chronic hypoxaemia may contribute to rapid shallow breathing in these patients. ${ }^{14}$ The weak but significant relationship between $\mathrm{TI}$ and $\mathrm{PaO}_{2}$ observed in our patients is in line with these observations. However, expressing TI as a combined function of PPLSW (\%PPLmin) and $\mathrm{PaO}_{2}$ did not significantly increase the ex- 
plained variance in $\mathrm{TI}$ beyond the contribution of Pplsw (\%Pplmin). Moreover, it has been reported that respiratory muscle fatigue induced by breathing against an inspiratory resistive load may result in a rapid and shallow breathing. ${ }^{32}$ However, muscle fatigue is an unlikely explanation for the short $T_{1}$ and the small VT we observed in hypercapnic patients during resting breathing. In line with previous studies which show that respiratory muscle fatigue can be demonstrated in less than $10 \%$ of patients with severe COPD during exacerbations of the disease, ${ }^{33}$ and in agreement with the study of Bégin and Grassino, ${ }^{12}$ the present results show that, in patients with severe COPD, PPLsw (\%PpLmin) was below $60 \%$ (fig 6) - that is, the threshold value associated with inspiratory muscle fatigue in normal subjects. ${ }^{34}$

Finally, it has recently been hypothesised that, in patients with chronic hypercapnic COPD, a rapid and shallow pattern of breathing is the result of an excessive load on the inspiratory muscles in relation to their maximal strength. ${ }^{1315}$ In this condition, shortening TI and reducing VT could be a strategy for reducing inspiratory muscle effort and distress and avoiding fatigue. ${ }^{13}$ In line with the concept that the perception of inspiratory effort and dyspnoea is closely linked to the pressure required for breathing relative to inspiratory muscle strength, ${ }^{35}$ it has also been suggested ${ }^{13}$ that a reduction in $T_{I}$ involves an integrated response of the respiratory system to the perception of breathlessness. Our data, which show an inverse relationship between $T_{I}$ and PPLSW (\%PrLmin) and a significant association between the severity of dyspnoea and both the increase in PPLSW (\%PPLmin) and the shortening in TI, strongly support the above hypotheses. These findings are also consistent with previous studies which have shown that breathlessness during exercise is significantly related to the PPLsw/MIP and TI/TTOT ratios both in normal subjects and in patients with cardiorespiratory disorders. ${ }^{3637}$ Furthermore, our data are in line with the observation that VT and respiratory timing responses to resistive loading are impaired in patients with COPD with severe inspiratory muscle weakness. ${ }^{38}$

In conclusion, we have shown that, in patients with stable COPD and severe airflow obstruction, chronic carbon dioxide retention is primarily associated with shallow breathing and inspiratory muscle weakness. It also appears that rapid, shallow breathing is mainly linked to both an excessive increase in the pressure required for breathing relative to inspiratory muscle strength, and to the severity of breathlessness.

This study was supported by grants from the Ministero dell'Università e della Ricerca Scientifica e Tecnologica of Italy.

1 Lane DJ, Howell JBL, Giblin B. Relation between airways obstruction and $\mathrm{CO}_{2}$ tension in chronic obstructive airways disease. $B M \mathcal{F}$ 1968;3:707-9.

2 West JB. Causes of carbon dioxide retention in lung disease. N Engl f Med 1971;284:1232-6.

3 Lourenco RV, Miranda JM. Drive and performance of the ventilatory apparatus in chronic obstructive lung disease. N Engl f Med 1968;279:53-9.
4 Mountain R, Zwillich C, Weil J. Hypoventilation in obstructive lung disease: the role of familial factors. $N$ Engl f Med 1978;298:521-5.

5 Rochester DF, Braun NMT. Determinants of maximal inspiratory pressure in chronic obstructive pulmonary disease. Am Rev Respir Dis 1985;132:42-7.

6 Gorini M, Spinelli A, Ginanni R, Duranti R, Gigliotti F, Scano G. Neural respiratory drive and neuromuscular coupling in patients with chronic obstructive pulmonary disease (COPD). Chest 1990;98:1179-86.

7 Sorli J, Grassino A, Lorange G, Milic-Emili J. Control of breathing in patients with chronic obstructive lung disease. Clin Sci Mol Med 1978;54:295-305.

8 Parot S, Saunier C, Gautier H, Milic-Emili J, Sadoul P. Breathing pattern in patients with chronic obstructive lung disease. Am Rev Respir Dis 1980;121:985-91.

9 Javaheri S, Blum J, Kazemi H. Pattern of breathing and carbon dioxide retention in chronic obstructive lung disease. Am F Med 1981;71:228-34.

10 Loveridge B, West P, Kriger MH, Anthonisen NR. Alteration in breathing pattern with progression of chronic obstructive pulmonary disease. Am Rev Respir Dis 1986;134:930-4.

11 Haluszka J, Chartrand DA, Grassino AE, Milic-Emili J. Intrinsic PEEP and arterial $\mathrm{PCO}_{2}$ in stable patients with chronic obstructive pulmonary disease. Am Rev Respir Dis 1990;141:1194-7.

12 Bégin P, Grassino A. Inspiratory muscle dysfunction and chronic hypercapnia in chronic obstructive pulmonary disease. Am Rev Respir Dis 1991;143:905-12.

13 Rochester D. Respiratory muscle weakness, pattern of breathing, and $\mathrm{CO}_{2}$ retention in chronic obstructive pulmonary disease. Am Rev Respir Dis 1991;143:901-3.

14 Bradley CA, Fleetham JA, Anthonisen NR. Ventilatory control in patients with hypoxemia due to obstructive lung disease. Am Rev Respir Dis 1979;120:21-30.

15 Roussos C, Moxham J. Respiratory muscle fatigue. In: Roussos C, Macklem PT, eds. The thorax (part B). New York: Marcel Dekker, 1985: 829-70.

16 American Thoracic Society. Standards for the diagnosis and care of patients with chronic obstructive pulmonary disease (COPD) and asthma. Am Rev Respir Dis 1987;136:225-44.

17 Metropolitan Life Insurance Company. New weight standards for men and women. New York: Metropolitan Life, 1983.

18 Minette A. Questionnaire of the European Community for Coal and Steel (ECSC) on respiratory symptoms. Eur Respir $\mathcal{F} 1989 ; 2: 165-77$.

19 European Community for Coal and Steel. Standardization of lung function test. Bull Eur Physiopathol Respir 1983; 19:1-95.

20 Agostoni E, Rahn $\mathrm{H}$. Abdominal and thoracic pressures at different lung volumes. F Appl Physiol 1960;15:1087-92.

21 Estenne $M$, Gorini $M$. Action of the diaphragm during cough in tetraplegic subjects. F Appl Physiol 1992;72:1074-80.

22 Frank NR, Mead J, Ferris BG Jr. The mechanical behaviour of the lungs in healthy elderly persons. $\mathcal{F}$ Clin Invest 1957 ; 36:1680-7.

23 Dal Vecchio L, Polese G, Poggi R, Rossi A. "Intrinsic" positive end-expiratory pressure in stable patients with chronic obstructive pulmonary disease. Eur Respir f 1990; 3:74-80.

24 Ninane V, Yernault JC, De Troyer A. Intrinsic PEEP in patients with chronic obstructive pulmonary disease: role of patients with chronic obstructive pulmonary disease: role of

25 De Troyer A, Yernault JC. Inspiratory muscle force in normal subjects and patients with chronic interstitial lung disease. Thorax 1980;35:92-100.

26 Laroche CM, Mier AK, Moxham J, Green M. The value of sniff esophageal pressures in the assessment of global inspiratory muscle strength. Am Rev Respir Dis 1988;138: 598-603.

27 Laporta D, Grassino A. Assessment of transdiaphragmatic pressure in humans. $\mathcal{F}$ Appl Physiol 1985;58:1469-76.

28 Gilbert R, Auchincloss JH, Brodsky J, Boden W. Changes in tidal volume, frequency, and ventilation induced by in tidal volume, frequency, and ventilation induced

29 Tobin MJ, Chadha TS, Jenouri G, Birch SJ, Gazeroglu HB, Sackner RA. Breathing patterns. 2. Diseased subjects. Chest 1983;84:286-94.

30 Juan G, Calverley P, Talamo C, Schnader J, Roussos C. Effect of carbon dioxide on diaphragmatic function in human beings. N Engl f Med 1984;310:874-9.

31 Weinberger SE, Schwartzstein RM, Weiss JW. Hypercapnia. $N$ Engl $\mathcal{Y}$ Med 1989;321:1223-31.

32 Gallagher CG, Im Hof V, Younes M. Effect of inspiratory muscle fatigue on breathing pattern. $\mathcal{f}$ Appl Physiol 1985; 59:1152-8.

33 Efthimiou J, Fleming J, Spiro SG. Sternomastoid muscle function and fatigue in breathless patients with severe respiratory disease. Am Rev Respir Dis 1987;136:1099-105.

34 Roussos C, Fixley M, Gross D, Macklem PT. Fatigue of the inspiratory muscles and their synergistic behaviour. $\mathcal{F}$ Appl Physiol 1977;46:897-904.

35 Killian KJ, Jones NL. Respiratory muscles and dyspnoea. Clin Chest Med 1988;9:237-48.

36 El-Manshawi A, Killian KJ, Summers E, Jones NL. Breathlessness during exercise with and without resistive loading. f Appl Physiol 1986;61:896-905.

37 Leblanc P, Bowie DM, Summers E, Jones NL, Killian KJ. Breathlessness and exercise in patients with cardiorespiratory disease. Am Rev Respir Dis 1986;133:21-5.

38 Oliven A, Kelsen SG, Chandler Deal E, Cherniack NS. Mechanism underlying $\mathrm{CO}_{2}$ retention during flow-resistive loading in patients with chronic obstructive pulmonary disease. $\mathcal{F}$ Clin Invest 1983;71:1442-9. 